\title{
The influence of Brand Image, Product Quality, and Price on Buying Decisions of Nissan Type Livina Cars
}

\author{
Rina Faja Taxvia, Riyadi*, Erika Devie \\ Jurusan Administrasi Bisnis, Politeknik Negeri Semarang, Jalan Prof. H. Soedarto, S.H. \\ Tembalang, Kota Semarang, 50275
}

\begin{abstract}
The consumer purchase decisions of Nissan Setiabudi Semarang Dealers to Nissan type Livina cars higher when compared to other types of Nissan cars, which can be seen from the car sales data of Nissan Setiabudi Semarang Dealers. Purchase decisions are influenced by several factors, including brand image, product quality, and price. The purpose of this research was to see the influence of brand image, product quality, and price on the purchase decision of Nissan type Livina cars at Nissan Setiabudi Semarang Dealers. The methods of collecting data were questionnaire, interview, and literature view. The data analysis used was multiple linier regression analysis. The number of samples in the research were 98 consumers. The results shows that the brand image partially had no significant effect on purchase decisions, while product quality and price had significant increase on purchase decisions. Then simultaneously the variables were brand image, product quality, and price had significant effect on purchase decisions. Based on results of multiple linier regression analysis, the equation $Y=1,199+$ $0,105 X 1+0,547 X 2+0,222 X 3$. Purchase decisions were explained by the variables of brand image, product quality, and price by $73,7 \%$, while the remaining $26,3 \%$ was explained by other variables not examined in this research.
\end{abstract}

Keywords : brand image, product quality, price, purchase decisions. 


\title{
Pengaruh Citra Merek, Kualitas Produk, dan Harga Terhadap Keputusan Pembelian Mobil Nissan Type Livina
}

\begin{abstract}
Abstrak
Keputusan pembelian konsumen Dealer Nissan Setiabudi Semarang terhadap mobil Nissan type Livina lebih tinggi jika dibandingkan dengan mobil Nissan type lainnya, yang mana dapat dilihat dari Data Penjualan Mobil Dealer Nissan Setiabudi Semarang. Keputusan pembelian dipengaruhi oleh beberapa faktor, diantaranya adalah citra merek, kualitas produk, dan harga. Tujuan dari penelitian ini adalah untuk mengetahui pengaruh Citra Merek, Kualitas Produk, dan Harga terhadap Keputusan Pembelian Mobil Nissan type Livina pada Dealer Nissan Setiabudi Semarang. Metode pengumpulan data yang digunakan dalam penelitian ini adalah kuesioner, wawancara dan studi pustaka. Analisis data menggunakan analisis regresi linier berganda. Jumlah sampel dalam penelitian ini adalah sebanyak 98 orang konsumen. Hasil penelitian menunjukkan bahwa secara parsial citra merek tidak berpengaruh signifikan terhadap keputusan pembelian, sedangkan kualitas produk dan harga berpengaruh signifikan terhadap keputusan pembelian. Kemudian secara simultan variabel citra merek, kualitas produk, dan harga berpengaruh signifikan terhadap keputusan pembelian. Berdasarkan hasil analisis regresi linier berganda diperoleh persamaan $\mathrm{Y}=1,199+0,105 \mathrm{X} 1+0,547 \mathrm{X} 2+0,222 \mathrm{X} 3$. Keputusan Pembelian dijelaskan oleh variabel citra merek, kualitas produk, dan harga sebesar 73,7\%, sedangkan sisanya sebesar $26,3 \%$ dijelaskan oleh variabel lain yang tidak diteliti dalam penelitian ini.
\end{abstract}

Kata kunci : citra merek, kualitas produk, harga, keputusan pembelian. 


\section{PENDAHULUAN}

Perkembangan zaman yang saat ini terus mengalami kemajuan dari waktu ke waktu telah berdampak pada berbagai bidang kehidupan. Salah satu bidang yang mengalami perkembangan cukup pesat adalah bidang teknologi. Perkembangan di bidang teknologi ini menjadikan masyarakat semakin mudah untuk mengakses jaringan internet dan memperoleh informasi dari berbagai hal baik dalam negeri maupun luar negeri. Dengan kemudahan yang diperoleh masyarakat tersebut akhirnya juga berdampak kepada para pelaku bisnis, karena konsumen menjadi lebih cerdas dan teliti dalam melakukan pembelian terhadap suatu produk. Bahkan tidak jarang dari mereka akan terlebih dahulu mencari informasi dari produk yang diinginkan sebelum memutuskan untuk membeli produk tersebut. Bagi para pelaku bisnis selain kemajuan teknologi ada hal lain yang perlu diperhatikan yaitu persaingan.

Di Indonesia sendiri terdapat banyak sekali merek mobil yang ditawarkan. Merekmerek mobil tersebut menawarkan berbagai desain, warna, kualitas, serta harga yang bervariasi. Hal ini tentunya berakibat pada semakin banyaknya pilihan merek mobil yang dapat dipilih oleh para konsumen sebelum memutuskan untuk melakukan pembelian. Terdapat banyak sekali faktor-faktor yang dapat mempengaruhi keputusan pembelian konsumen. Diantaranya adalah citra merek, kualitas produk, dan harga. Konsumen dengan citra yang positif terhadap suatu merek, akan lebih memungkinkan untuk melakukan pembelian (Setiadi, dikutip dalam Aini dkk, 2018). Kemudian menurut Kotler dan Keller (dikutip dalam Indah dkk, 2020) mengemukanan bahwa semakin berkualitas produk maka semakin tinggi keputusan konsumen untuk melakukan pembelian produk. Sedangkan harga merupakan faktor yang penting baik bagi penjual ataupun pembeli. Menurut Tjiptono (dikutip dalam Maindoka dkk, 2018) penetapan harga secara tepat merupakan faktor penting dalam menentukan kesuksesan perusahaan dalam jangka pendek dan jangka panjang.

Mobil merek Nissan termasuk salah satu mobil yang terkenal di Indonesia dan memiliki berbagai type mobil yang ditawarkan diantaranya adalah Livina, Terra, March, Juke dan Xtrail. Namun beberapa tahun terakhir diketahui bahwa penjualan mobil Nissan mulai menukik. Berdasarkan data penjualan tahun 2015 hingga tahun 2019 mobil merek Nissan mengalami penurunan penjualan, dan penurunan terendah terjadi pada tahun 2018. Meskipun mengalami penurunan penjualan, namun hingga saat ini Nissan tetap dapat bertahan dan bersaing dengan perusahaan otomotif lainnya. Hal ini dikarenakan Nissan memiliki salah satu type mobil yang paling diminati dan mampu menarik perhatian konsumen yaitu mobil Nissan type Livina. Dari data penjualan mobil Dealer Nissan Setiabudi Semarang dari tahun 2017 hingga tahun 2019 diketahui bahwa mobil Nissan type Livina memilliki tingkat penjualan yang lebih tinggi dibandingkan dengan mobil Nissan type lainnya. Berdasarkan uraian tersebut menunjukkan bahwa mobil Nissan type Livina memiliki daya tarik yang cukup besar terhadap pembelian konsumen. Untuk itu penulis tertarik melakukan penelitian dengan judul "Pengaruh Citra Merek, Kualitas Produk, dan Harga Terhadap Keputusan Pembelian Mobil Nissan Livina (Studi Kasus Pada Dealer Nissan Setiabudi Semarang)".

\section{Rumusan Masalah}

1. Bagaimana pengaruh Citra Merek terhadap Keputusan Pembelian konsumen Mobil Nissan type Livina pada Dealer Nissan Setiabudi Semarang?

2. Bagaimana pengaruh Kualitas Produk terhadap Keputusan Pembelian konsumen Mobil Nissan type Livina pada Dealer Nissan Setiabudi Semarang?

3. Bagaimana pengaruh Harga terhadap Keputusan Pembelian konsumen Mobil Nissan type Livina pada Dealer Nissan Setiabudi Semarang? 
4. Bagaimana pengaruh Citra Merek, Kualitas Produk, dan Harga terhadap Keputusan Pembelian konsumen Mobil Nissan type Livina pada Dealer Nissan Setiabudi Semarang?

\section{Tujuan Penelitian}

1. Menganalisis pengaruh citra merek terhadap keputusan pembelian konsumen Mobil Nissan type Livina pada Dealer Nissan Setiabudi Semarang.

2. Menganalisis pengaruh kualitas produk terhadap keputusan pembelian konsumen Mobil Nissan type Livina pada Dealer Nissan Setiabudi Semarang.

3. Menganalisis pengaruh harga terhadap keputusan pembelian konsumen Mobil Nissan type Livina pada Dealer Nissan Setiabudi Semarang.

4. Menganalisis pengaruh citra merek, kualitas produk, dan harga terhadap keputusan pembelian konsumen Mobil Nissan type Livina pada Dealer Nissan Setiabudi Semarang.

\section{Tinjauan Pustaka}

\section{Keputusan Pembelian}

Menurut Kotler \& Keller (dikutip dalam Indraprasta, 2019) Keputusan pembelian adalah sebuah proses dimana konsumen mulai mengetahui masalahnya, selanjutnya mencari informasi produk atau merek dan mengevaluasi masing-masing pilihan yang dapat menyelesaikan masalah tersebut sehingga mengarah pada keputusan pembelian. Keputusan pembelian sangat penting dilakukan ketika ada banyak pilihan dengan fungsi yang sama untuk suatu barang (Monroe, dikutip dalam Amron, 2018).

\section{Indikator Keputusan Pembelian}

Menurut Soewito (dikutip dalam Harahap, 2015) indikator keputusan pembelian adalah sebagai berikut :

1. Kebutuhan yang dirasakan.

2. Kegiatan sebelum membeli.

3. Perilaku waktu memakai.

4. Perilaku pasca pembelian.

\section{Citra Merek}

Menurut Tjiptono (dikutip dalam Maindoka dkk, 2018) Citra merek adalah deskripsi asosiasi dan keyakinan konsumen terhadap merek tertentu. Kemudian Kotler dan Keller (dikutip dalam Adaming, 2019) mengemmukanan bahwa citra merek adalah penilaian konsumen terhadap merek tersebut dalam sebuah pasar. Penilaian tersebut dapat tercipta berdasarkan pengalaman pribadi maupun mendengar reputasinya dari orang lain atau media.

\section{Indikator Citra Merek}

Menurut Aaker dan Biel (dikutip dalam Supriyadi dkk, 2016) Indikatorindikator yang dapat membentuk Citra Merek adalah sebagai berikut :

1. Citra pembuat (Corporate Image), sekumpulan asosiasi yang dipersepsikan konsumen terhadap perusahaan yang membuat suatu barang atau jasa.

2. Citra produk / konsumen (Product Image), sekumpulan asosiasi yang dipersepsikan konsumen terhadap suatu barang atau jasa.

3. Citra pemakai (User Image), sekumpulan asosiasi yang dipersepsikan konsumen terhadap pemakai yang menggunakan suatu barang atau jasa.

\section{Kualitas Produk}

Menurut Kotler dan Amstrong (dikutip dalam Sari, 2017) Kualitas produk adalah kemampuan suatu barang untuk memberikan hasil atau kinerja yang sesuai bahkan melebihi apa yang diinginkan pelanggan.

\section{Indikator Kualitas Produk}

Menurut Orvile, dkk (dikutip dalam Riyono dkk, 2016) indikator-indikator yang dapat digunakan untuk mengukur kualitas produk adalah sebagai berikut :

1. Performance (kinerja), berhubungan dengan karakteristik operasi dasar dari sebuah produk. 
2. Durability (daya tahan), berapa lama umur produk yang bersangkutan bertahan sebelum produk tersebut harus diganti.

3. Conformance to Specifications (kesesuaian dengan spesifikasi), sejauh mana karakteristik operasi dasar dari sebuah produk memenuhi spesifikasi tertentu dari konsumen atau tidak ditemukannya cacat pada produk.

4. Features (fitur), karakteristik produk yang dirancang untuk menyempurnakan fungsi produk atau menambah ketertarikan konsumen terhadap produk.

5. Reliabilty (reliabilitas), probabilitas bahwa produk akan bekerja dengan memuaskan atau tidak dalam periode waktu tertentu.

6. Aesthetics (estetika), berhubungan dengan bagaimana penampilan produk bisa dilihat dari tampak dan bentuk dari produk.

7. Perceived Quality (kesan kualitas), merupakan hasil dari pengukuran yang dilakukan secara tidak langsung. Sehingga dapat dikatakan sebagai persepsi konsumen terhadap produk didapat dari harga, merek, periklanan, reputasi, dan Negara asal.

\section{Harga}

Menurut Kotler \& Amstrong (dikutip dalam Indraprasta, 2019) Harga adalah sejumlah uang yang dikeluarkan untuk sebuah produk atau jasa, atau sejumlah nilai yang ditukarkan oleh konsumen untuk memperoleh manfaat atau kepemilikan atas penggunaan sebuah produk atau jasa.

\section{Indikator Harga}

Menurut Kotler dan Armstrong (dikutip dalam Riyono dkk, 2016), terdapat empat indikator yang mencirikan harga yaitu sebagai berikut :

1. Keterjangkauan harga.

2. Kesesuaian harga dengan kualitas.
3. Daya saing harga.

4. Kesesuaian harga dengan manfaat.

\section{METODE PENELITIAN \\ Populasi dan Sampel}

Di dalam penelitian ini, yang menjadi populasi yaitu konsumen mobil Nissan type Livina tahun 2019 pada Dealer Nissan Setiabudi Semarang yang berjumlah 98 orang. Teknik sampel yang digunakan yaitu sampling jenuh sehingga sampel yang digunakan berjumlah 98 responden.

\section{Teknik Pengumpulan Data}

Teknik pengumpulan data yang digunakan dalam penelitian ini yaitu wawancara, kuesioner, dan studi pustaka. Kuesioner dalam penelitian ini menggunakan skala pengukuran Semantic Defferensial dengan rentang 1-10 untuk setiap pertanyaan.

Teknik Analisis Data

Teknik analisis yang digunakan dalam penelitian ini yaitu analisis regresi linear berganda. Hasil analisis data terdiri dari uji instumen validitas dan reliabilitas, uji asumsi klasik, uji hipotesis (Uji t dan Uji F), serta koefisien determinasi.

\section{HASIL DAN PEMBAHASAN Uji Validitas}

Uji validitas digunakan untuk mengetahui kelayakan butir-butir dalam suatu daftar pertanyaan dalam mendefinisikan suatu variabel (Sujarweni, 2019:192). Uji validitas dapat dilakukan dengan cara membandingkan antara nilai $r$ hitung dengan $r$ tabel. Butir item pertanyaan dinyatakan valid jika koefisien $r$ hitung > $r$ tabel. Diperoleh dari daftar $r$ tabel dengan $\mathrm{df}=\mathrm{n}-2$, yaitu (30-2) sehingga $\mathrm{df}=28$ dan dapat diketahui bahwa hasil $\mathrm{r}$ tabel adalah 0,3610 . 
Tabel 1 Uji Validitas

\begin{tabular}{|c|c|c|c|c|}
\hline Variabel & Pertanyaan & $\mathbf{r}_{\text {hitung }}$ & $\mathbf{r}_{\text {tabel }}$ & Keterangan \\
\hline \multirow{6}{*}{$\begin{array}{c}\text { Citra } \\
\text { Merek (X1) }\end{array}$} & X1.1 & 0.459 & 0.361 & Valid \\
\hline & $\mathrm{X} 1.2$ & 0.583 & 0.361 & Valid \\
\hline & $\mathrm{X} 1.3$ & 0.681 & 0.361 & Valid \\
\hline & X1.4 & 0.489 & 0.361 & Valid \\
\hline & $\mathrm{X} 1.5$ & 0.576 & 0.361 & Valid \\
\hline & X1.6 & 0.529 & 0.361 & Valid \\
\hline \multirow{14}{*}{$\begin{array}{c}\text { Kualitas } \\
\text { Produk } \\
\text { (X2) }\end{array}$} & $\mathrm{X} 2.1$ & 0.423 & 0.361 & Valid \\
\hline & $\mathrm{X} 2.2$ & 0.625 & 0.361 & Valid \\
\hline & $\mathrm{X} 2.3$ & 0.605 & 0.361 & Valid \\
\hline & $\mathrm{X} 2.4$ & 0.530 & 0.361 & Valid \\
\hline & $\mathrm{X} 2.5$ & 0.567 & 0.361 & Valid \\
\hline & $\mathrm{X} 2.6$ & 0.533 & 0.361 & Valid \\
\hline & $\mathrm{X} 2.7$ & 0.494 & 0.361 & Valid \\
\hline & $\mathrm{X} 2.8$ & 0.787 & 0.361 & Valid \\
\hline & X2.9 & 0.515 & 0.361 & Valid \\
\hline & $\mathrm{X} 2.10$ & 0.714 & 0.361 & Valid \\
\hline & $\mathrm{X} 2.11$ & 0.674 & 0.361 & Valid \\
\hline & $\mathrm{X} 2.12$ & 0.745 & 0.361 & Valid \\
\hline & X2.13 & 0.607 & 0.361 & Valid \\
\hline & X2.14 & 0.583 & 0.361 & Valid \\
\hline \multirow{8}{*}{$\begin{array}{c}\text { Harga } \\
\text { (X3) }\end{array}$} & X3.1 & 0.802 & 0.361 & Valid \\
\hline & $\mathrm{X} 3.2$ & 0.760 & 0.361 & Valid \\
\hline & $\mathrm{X} 3.3$ & 0.692 & 0.361 & Valid \\
\hline & X3.4 & 0.741 & 0.361 & Valid \\
\hline & $\mathrm{X} 3.5$ & 0.796 & 0.361 & Valid \\
\hline & X3.6 & 0.860 & 0.361 & Valid \\
\hline & X3.7 & 0.752 & 0.361 & Valid \\
\hline & X3.8 & 0.691 & 0.361 & Valid \\
\hline \multirow{8}{*}{$\begin{array}{c}\text { Keputusan } \\
\text { Pembelian } \\
\text { (Y) }\end{array}$} & Y.1 & 0.640 & 0.361 & Valid \\
\hline & Y.2 & 0.757 & 0.361 & Valid \\
\hline & Y.3 & 0.570 & 0.361 & Valid \\
\hline & Y.4 & 0.793 & 0.361 & Valid \\
\hline & Y.5 & 0.712 & 0.361 & Valid \\
\hline & Y.6 & 0.773 & 0.361 & Valid \\
\hline & Y.7 & 0.620 & 0.361 & Valid \\
\hline & Y.8 & 0.647 & 0.361 & Valid \\
\hline
\end{tabular}

Sumber : Data primer yang diolah, 2020

Berdasarkan hasil uji validitas Tabel 1, dapat diketahui bahwa seluruh butir pertanyaan yang digunakan untuk masingmasing variabel memiliki nilai $r$ hitung $>r$ tabel $(0,361)$. Sehingga dapat dinyatakan bahwa seluruh butir pertanyaan yang digunakan valid.

\section{Uji Reliabilitas}

Uji Reliabilitas merupakan ukuran suatu kestabilan dan konsistensi responden 
dalam menjawab butir-butir pertanyaan pada kuisioner. Jika hasil dari cronbach alpha memiliki nilai > 0,60 maka data dinyatakan reliable (Ramadhayanti, 2019:86). Pada Tabel 2, merupakan hasil dari uji reliabilitas.

Tabel 2 Uji Reliabilitas

\begin{tabular}{|l|c|c|l|}
\hline \multicolumn{1}{|c|}{ Variabel } & $\begin{array}{c}\text { Cronbach's } \\
\text { Alpha }\end{array}$ & $\begin{array}{c}\text { Nilai } \\
\text { Alpha }\end{array}$ & \multicolumn{1}{|c|}{ Keterangan } \\
\hline Citra Merek (X1) & 0.738 & 0.60 & Reliabel \\
\hline Kualitas Produk (X2) & 0.888 & 0.60 & Reliabel \\
\hline Harga (X3) & 0.915 & 0.60 & Reliabel \\
\hline $\begin{array}{l}\text { Keputusan Pembelian } \\
\text { (Y) }\end{array}$ & 0.889 & 0.60 & Reliabel \\
\hline
\end{tabular}

Sumber: Data primer yang diolah, 2020

Berdasarkan hasil uji reliabilitas Tabel 2, dapat diketahui bahwa nilai Cronbach Alpha dari semua variabel lebih besar dari nilai Alpha 0,60 yang artinya bahwa instrumen yang digunakan dalam penelitian ini adalah reliabel atau handal untuk digunakan.

\section{Uji Asumsi Klasik} Uji Normalitas

Uji Normalitas dilakukan untuk melihat apakah dalam model regresi variabel terikat dan variabel bebas, keduanya mempunyai distribusi normal atau tidak (Ramadhayanti, 2019:147). Berikut adalah dua cara untuk mengetahui apakah suatu model regresi berdistribusi normal atau tidak.

\section{Analisis Grafik}

\section{Gambar 1 Grafik P-Plot Uji Normalitas}

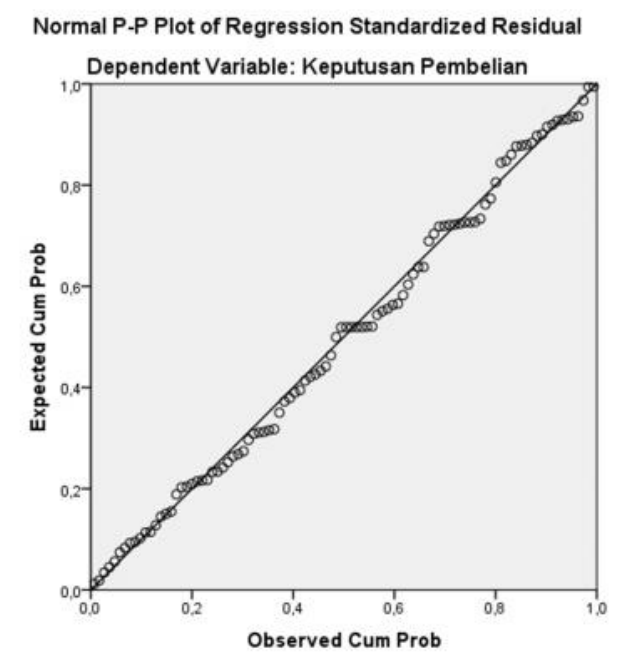

Sumber : Output SPSS 24.0 (2020)

Berdasarkan gambar 1 grafik Normal Probability Plot dapat dilihat bahwa titik-titik menyebar di sekitar garis diagonal dan mengikuti arah garis diagonal. Sehingga hasil tersebut menunjukkan bahwa model regresi yang digunakan memenuhi asumsi normalitas yang ada. 


\section{Analisis Statistik}

Tabel 3 Hasil Uji Kolmogrov-Sminrov

\begin{tabular}{|ll|r|}
\hline & & \multicolumn{1}{|c|}{$\begin{array}{c}\text { Unstandardized } \\
\text { Residual }\end{array}$} \\
\hline $\mathrm{N}$ & & 98 \\
\hline Normal Parameters & Mean &, 0000000 \\
\hline & Std. Deviation &, 33728035 \\
\hline Most Extreme Differences & Absolute &, 052 \\
\hline & Positive &, 052 \\
\hline & Negative &,- 044 \\
\hline Test Statistic & &, 052 \\
\hline Asymp. Sig. (2-tailed) & &, $200^{\text {c,d }}$ \\
\hline
\end{tabular}

Sumber : Output SPSS 24.0, 2020

Berdasarkan hasil uji kolmogrovsmirnov Tabel 3, dapat diketahui bahwa nilai signifikansi sebesar $0,200>0,05$. Sehingga dapat dinyatakan bahwa seluruh data atau model regresi yang digunakan berdistribusi normal.

\section{Uji Multikolinearitas}

Uji Multikolinearitas digunakan untuk mengetahui apakah pada model regresi ditemukan adanya korelasi antar variabel bebas atau variabel independen (Ramadhayanti, 2019:137).

Tabel 4 Hasil Uji Multikolinearitas

\begin{tabular}{|l|c|c|}
\hline \multirow{2}{*}{\multicolumn{1}{|c|}{ Variabel }} & \multicolumn{2}{c|}{ Kolinearitas Statistik } \\
\cline { 2 - 3 } & Nilai Tolerance & Nilai VIF \\
\hline Citra Merek (X1) & 0,441 & 2,223 \\
\hline Kualitas Produk (X2) & 0,400 & 2,450 \\
\hline Harga (X3) & 0,584 & 1,713 \\
\hline Variabel Dependen : Keputusan Pembelian (Y) \\
\hline
\end{tabular}

Sumber : Data primer yang diolah, 2020

Berdasarkan tabel 4 hasil uji multikolinearitas dapat diketahui bahwa masing-masing variabel memiliki nilai VIF berkisar antara 1-10 atau < 10. Sehingga dapat dikatakan bahwa pada model regresi tidak terjadi multikolinearitas.

\section{Uji Heteroskedastisitas}

Uji Heteroskedastisitas digunakan untuk mengetahui apakah terjadi perbedaan variance residual suatu periode pengamatan ke periode pengamatan yang lain (Sujarweni, 2019:186). 


\section{Gambar 2 Hasil Uji Heteroskedastisitas}

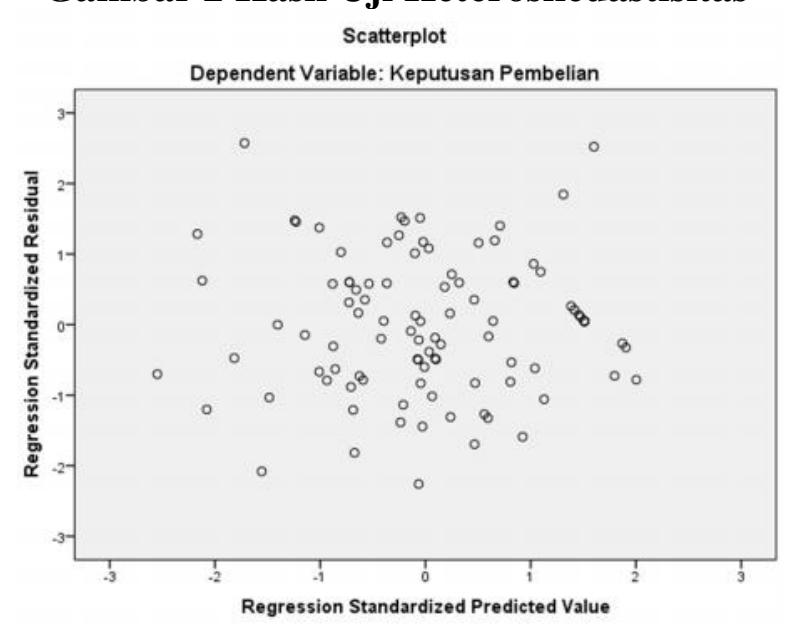

Sumber : Output SPSS 24.0 (2020)

Berdasarkan gambar 2 scatterplot menunjukkan bahwa titik-titik data menyebar di atas dan di bawah atau disekitar angka 0 , kemudian tidak menggumpul hanya di atas atau di bawah saja, dan penyebaran titik-titik data tidak membentuk suatu pola. Sehingga dengan begitu dapat dinyatakan bahwa dalam penelitian ini tidak terjadi heteroskedastisitas.

\section{Analisis Regresi Linier Berganda}

Uji regresi bertujuan untuk mengetahui besarnya pengaruh variabel bebas (independent) terhadap variabel terikat (dependent).

Tabel 5 Hasil Uji Analisis Regresi Linier Berganda

\begin{tabular}{|c|c|c|c|c|c|c|}
\hline \multirow{2}{*}{\multicolumn{2}{|c|}{ Model }} & \multicolumn{2}{|c|}{$\begin{array}{l}\text { Unstandardized } \\
\text { Coefficients }\end{array}$} & \multirow{2}{*}{\begin{tabular}{|c|c}
$\begin{array}{c}\text { Standardize } \\
\mathrm{d} \\
\text { Coefficients }\end{array}$ \\
Beta \\
\end{tabular}} & \multirow[b]{2}{*}{$\mathrm{T}$} & \multirow[b]{2}{*}{ Sig. } \\
\hline & & B & Std. Error & & & \\
\hline \multirow[t]{4}{*}{1} & (Constant) & 1,119 &, 433 & & 2,586 &, 011 \\
\hline & Citra Merek (X1) & , 105 & ,067 & ,122 & 1,570 & 120 \\
\hline & $\begin{array}{l}\text { Kualitas Produk } \\
\text { (X2) }\end{array}$ & ,547 & ,081 & ,547 & 6,723 & ,000 \\
\hline & Harga (X3) & ,222 & ,051 & 299 & 4,388 & ,000 \\
\hline \multicolumn{2}{|c|}{ F hitung } & \multicolumn{5}{|l|}{91,841} \\
\hline \multicolumn{2}{|c|}{ Adjusted R Square } & ,737 & & & & \\
\hline
\end{tabular}

Sumber : Data primer yang diolah (2020)

Berdasarkan Tabel 5 hasil uji analisis regresi linier berganda, maka diperoleh persamaan:

$$
Y=1,199+0,105 X 1+0,547 X 2+0,222 X 3
$$

Hasil persamaan regresi linier berganda dapat dijelaskan dengan pengertian sebagai berikut : 1. Nilai Konstanta 1,199, artinya apabila variabel citra merek (X1), variabel kualitas produk (X2), dan variabel harga (X3) nilainya adalah 0 , maka variabel keputusan pembelian (Y) nilainya adalah 1,199.

2. Nilai Koefisien $X 1$ atau variabel citra merek 0,105. Berdasarkan uji parsial tidak berpengaruh signigikan terhadap keputusan pembelian (Y).

3. Nilai Koefisien $\mathrm{X} 2$ atau variabel kualitas produk 0,547 , artinya setiap kenaikan 
variabel kualitas produk (X2) akan meningkatkan keputusan pembelian sebesar 0,547. Dengan asumsi variabel citra merek dan harga tetap atau tidak berubah.

4. Nilai Koefisien X3 atau variabel harga 0,222 , artinya setiap kenaikan variabel harga (X3) akan meningkatkan keputusan pembelian sebesar 0,222. Dengan asumsi variabel citra merek dan kualitas produk tetap atau tidak berubah.

\section{Uji Hipotesis}

\section{Uji Parsial (Uji t)}

Uji t (T Test) digunakan untuk mengetahui seberapa besar pengaruh dari masing-masing variabel bebas terhadap variabel terikat. Berdasarkan Tabel 5 diketahui bahwa variabel kualitas produk dan harga memiliki nilai $\mathrm{t}$ hitung > t tabel, sehingga dapat disimpulkan bahwa variabel kualitas produk dan harga berpengaruh signifikan terhadap keputusan pembelian. Sedangkan variabel citra merek memiliki nilai $\mathrm{t}$ hitung $<\mathrm{t}$ tabel, sehingga dapat disimpulkan bahwa citra merek tidak berpengaruh signifikan terhadap keputusan pembelian.

\section{Uji Simultan (Uji F)}

Uji F digunakan untuk mengetahui pengaruh variabel bebas secara serentak atau bersamasama terhadap variabel terikat. Berdasarkan Tabel 5 diketahui bahwa nilai $\mathrm{F}$ hitung adalah $91,841>\mathrm{F}$ tabel $(2,70)$. Sehingga dapat disimpulkan bahwa secara bersama-sama variabel citra merek, kualitas produk, dan harga berpengaruh signifikan terhadap keputusan pembelian.

\section{Koefisien Determinasi}

Koefisien determinan $\left(\mathrm{R}^{2}\right)$ bertujuan untuk mengetahui seberapa besar kemampuan variabel independen dalam menjelaskan variabel dependen (Nugroho, 2005:50). Dari Tabel 5 dapat diketahui bahwa nilai Adjusted $R$ Square adalah sebesar 0,737 atau $73,7 \%$. Untuk itu dapat disimpulkan bahwa variabel independent yang terdiri dari citra merek, kualitas produk, dan harga mampu menjelaskan variabel dependent yaitu keputusan pembelian sebesar 73,7\%. Sedangkan sisanya dijelaskan oleh variabel lain yang tidak diteliti dalam penelitian ini.

\section{SIMPULAN}

1. Berdasarkan Uji secara Parsial tidak terdapat pengaruh yang signifikan antara variabel citra merek terhadap keputusan pembelian konsumen mobil Nissan type Livina pada Dealer Nissan Setiabudi Semarang. Sedangkan untuk variabel kualitas produk dan harga terdapat pengaruh yang signifikan terhadap keputusan pembelian konsumen mobil Nissan type Livina pada Dealer Nissan Setiabudi Semarang.

2. Secara simultan variabel Citra Merek, Kualitas Produk, dan Harga berpengaruh signifikan terhadap Keputusan Pembelian konsumen mobil Nissan type Livina pada Dealer Nissan Setiabudi Semarang.

3. Nilai Adjusted $R$ Square atau $\mathrm{R}$ Square yang telah disesuaikan adalah sebesar $73,7 \%$ untuk variabel citra merek, kualitas produk, dan harga dapat menjelaskan variabel keputusan pembelian. Sedangkan sisanya 26,3\% dijelaskan oleh variabel lain yang tidak diteliti dalam penelitian ini.

\section{Saran}

Dari hasil penelitian yang telah dilakukan, terdapat beberapa saran yang dapat diberikan kepada Nissan khususnya Dealer Nissan Setiabudi Semarang, yaitu sebagai berikut:

1. Perlu bagi Nissan untuk memberikan perhatian lebih terhadap kualitas produk dari mobil Nissan type Livina agar dapat meningkatkan keputusan pembelian konsumen. Hal ini dikarenakan kualitas produk memiliki pengaruh besar terhadap keputusan pembelian mobil Nissan type Livina. Untuk itu perusahaan dapat meningkatkan kualitas produk yang ada seperti kualitas kinerja mesin, kualitas 
sparepart, kemudian fitur-fitur yang melengkapi, serta inovasi terhadap desain/estetika pada mobil Nissan type Livina.

2. Kemudian harga juga memiliki peranan penting untuk diperhatikan. Karena harga memiliki pengaruh yang signifikan terhadap keputusan pembelian. Sehingga sangat penting bagi Nissan untuk memperhatikan penetapan harga pada mobil Nissan Livina agar dapat dijangkau oleh berbagai kalangan konsumen dengan tingkat daya beli yang sedang ataupun tinggi.

3. Diharapkan Dealer Nissan Setiabudi Semarang dapat selalu menjaga citra merek yang ada. Hal ini sangat perlu, dikarenakan saat ini tingkat persaingan usaha di bidang otomotif semakin tinggi. Selain itu, pihak Dealer Nissan Setiabudi Semarang juga perlu untuk menjalin hubungan baik serta melakukan pengenalan produk dengan para konsumen, yang diharapkan dapat lebih meningkatkan keputusan pembelian konsumen terhadap mobil Nissan type Livina.

\section{DAFTAR PUSTAKA}

Adaming, Satriani. 2019. Pengaruh Citra Merek, Kualitas Produk dan Persepsi Harga terhadap Keputusan Pembelian Pada Produk Ponsel Iphone (Studi Pada Mahasiswa Pendidikan Ekonomi Universitas Negeri Makassar).

Aini, Laifatul Mufaricha Nur, dkk. 2018. Pengaruh Citra Merek, Kualitas Produk dan Harga terhadap Keputusan Pembelian Sabun Dettol di Sidoarjo. Jurnal Manajemen Branchmarck, Vol.4, (1), 2018.

http://eprints.ubhara.ac.id/84/ (20 April 2020).

Amron. 2018. The Influence of Brand Image, Brand Trust, Product Quality, and Price on the Consumer's Buying Decision of MPV Cars. http://eujournal.org/index.php/esj/article/ view/10830 (1 Juni 2020).

Harahap, Dedy Ansari. 2015. Analisis FaktorFaktor yang mempengaruhi Keputusan Pembelian Konsumen di Pajak USU (Pajus) Medan. Jurnal Keuangan dan Bisnis, Vol.7, (3), 2015. https://ecojoin.org/index.php/EJM/article/ view/312 (22 April 2020).

Indah, Dewi Rosa, dkk. 2020. Pengaruh Citra Merek, Kualitas Produk dan Harga terhadap Keputusan Pembelian Produk Hand and Body Lotion Vaseline (Studi Kasus pada Mahasiswa Universitas Samudra). Jurnal Samudra Ekonomi dan Bisnis, Vol.11, (1), 2020.

https://www.ejurnalunsam.id/index.php/js eb/article/view/1983 (10 April 2020).

Indaprasta, Dwireno Galih. 2019. Pengaruh Citra Merek, Kualitas Produk dan Harga terhadap Keputusan Pembelian Pada Sepatu Converse di Artos Mall Magelang.

Maindoka, Lifia Filia, dkk. 2018. Analisis Pengaruh Citra Merek, Harga dan Desain Produk terhadap Keputusan Pembelian Mobil Nissan Grand Livina Pada PT Wahana Wirawan Manado. Jurnal EMBA, Vol.6, (3), 2018.

https://ejournal.unsrat.ac.id/index.php/em ba/article/view/2023 (3 April 2020).

Nugroho, Bhuono Agung. 2005. Strategi Jitu Memilih Metode Statistik Penelitian dengan SPSS. Yogyakarta: C.V. Andi Offset.

Priyatno, Duwi. 2010. Paham Analisa Statistika Data dengan SPSS. Yogyakarta: MediaKom.

Ramadhayanti, Ana, 2019. Aplikasi SPSS untuk Penelitian dan Riset Pasar. Jakarta: PT Elex Media Komputindo.

Riyono, dan Gigih Erlik Budiharja. 2016. Pengaruh Kualitas Produk, Harga, Promosi dan Brand Image Terhadap Keputusan Pembelian Produk AQUA di Kota Pati. Jurnal STIE Semarang, Vol.8, (2), 2016. 
http://jurnal3.stiesemarang.ac.id/index.ph p/jurnal/article/view/42 (22 April 2020).

Sari, Venia Afrilia. 2017. Pengaruh Harga, Kualitas Produk dan Citra Merek terhadap Keputusan Pembelian Teh Siap Minum Dalam Kemasan Teh Botol Sosro. Diponegoro University Journal of Social and Politic, Business Administration. 2017.

https://ejournal3.undip.ac.id/index.php/jia b/article/viewFile/16738/16077

(1 Mei 2020).
Sujarweni, V. Wiratna. 2019. SPSS Untuk Penelitian. Yogyakarta: Pustaka Baru Press.

Supriyadi, dkk. 2016. Pengaruh Kualitas Produk dan Brand Image terhadap Keputusan Pembelian (Studi pada Mahasiswa Pengguna Produk Sepatu Merek Converse di Fisip Universitas Merdeka Malang). Jurnal Bisnis dan Manajemen, Vol.3, (1), 2016. http://jurnal.unmer.ac.id/index.php/jbm/a rticle/view/1714 (22 April 2020) 